\title{
INELASTIC RESPONSE MODES OF SEISMICALLY ISOLATED STRUCTURES: FAILURE OF THE ISOLATORS OR DAMAGE IN THE ISOLATED STRUCTURE?
}

\author{
Anastasios Tsiavos $^{1}$, Tomislav Markic ${ }^{2}$, David Schlatter ${ }^{3}$ and Bozidar Stojadinovic ${ }^{4}$ \\ ${ }^{1}$ Lecturer, Department of Civil, Environmental and Geomatic Engineering, ETH Zurich, Switzerland \\ e-mail: tsiavos@ibk.baug.ethz.ch \\ ${ }^{2} \mathrm{PhD}$ Student, Department of Civil, Environmental and Geomatic Engineering, ETH Zurich, \\ Switzerland \\ e-mail: markic@ibk.baug.ethz.ch \\ ${ }^{3}$ Master Student, Department of Civil, Environmental and Geomatic Engineering, ETH Zurich, \\ Switzerland \\ e-mail: dschlatter@student.ethz.ch \\ ${ }^{4}$ Professor, Department of Civil, Environmental and Geomatic Engineering, ETH Zurich, Switzerland \\ e-mail: stojadinovic@ibk.baug.ethz.ch
}

\begin{abstract}
The goal of this study is to determine experimentally the inelastic response modes of seismically isolated structures. A steel specimen is designed and constructed to simulate the dynamic behavior of a Single-Degree-Of-Freedom (SDOF) system. The specimen is seismically isolated with four friction pendulum bearings and excited by a group of earthquake ground motion records using the shaking table of ETH Zurich Laboratory. A mechanical clevis connection consisting of two hinges and two replaceable steel coupons is designed and constructed to facilitate the parametric investigation of the inelastic response of the isolated structure for varying values of its strength. Two fundamentally different inelastic response modes have been observed during the excitation of the structure: A response mode dominated by large sliding displacement demand in the isolators and a response mode characterized by large displacement ductility demand in the isolated structure. This paper shows the effect of the design parameters of the isolation system and the isolated structure on the manifestation of these two response modes, thus paving the way for the understanding of the inelastic response of seismically isolated structures subjected to extreme earthquake ground motions.
\end{abstract}

Keywords: seismic isolation, shaking table tests, friction pendulum bearings, inelastic behavior of seismically isolated structures 


\section{INTRODUCTION}

The attractive characteristics of seismic isolation on the seismic protection of structures through the use of frictional or elastomeric devices have been demonstrated by many researchers in the past [1-3]. The current seismic code provisions prescribe the elastic design of these structures for a design-basis earthquake event. In view of these provisions, most of the existing studies investigating the dynamic response of seismically isolated structures use an elastic dynamic model for the simulation of the seismic response of the isolated structure.

However, seismically isolated structures can be subjected to inelastic behavior and damage, when they are excited by earthquake ground motion with intensities exceeding the design seismic hazard level. Furthermore, seismically isolated structures can manifest inelastic behavior even for ground motion intensities corresponding to the design hazard level, when they are unintentionally constructed with lower strength than the value prescribed by the code provisions [4-7]. The investigation of such behavior of existing seismically isolated structures sheds light on their reliability and robustness compared to fixed-based structures, as defined by Castaldo et al. [8,9], Tsang [10] and Peng et al. [11].

In view of these challenges, the inelastic behavior of seismically isolated structures has been investigated in several studies in the past. Kikuchi et al. [12] and Cardone et al. [13] investigated analytically the inelastic behavior of seismically isolated structures, concluding that the behavior of these structures after they yield is substantially different from the corresponding fixed-based structures. Ragni et al. [14] presented the seismic damage and collapse risk of seismically isolated buildings, designed according to the Italian seismic code provisions. Tsiavos et al. [15] determined analytically and verified experimentally $[16,17]$ the relations between the strength reduction factor $R_{y}$, the ductility demand $\mu$ and the fixed-based vibration period $T_{n}$ of seismically isolated structures.

Nevertheless, these studies did not focus on the two different failure types that characterize the inelastic behavior of seismically isolated structures: The failure of the isolators and the occurrence of damage in the isolated structure.

Along these lines, the present study aims to illustrate experimentally the design parameters that lead to the two different failure types of seismically isolated structures. A steel structure is seismically isolated with four friction pendulum bearings and subjected to an ensemble of recorded, unidirectional earthquake ground motion excitations. The design and construction of a mechanical clevis connection allows the variation of the strength of the isolated structure.

\section{EXPERIMENTAL CONFIGURATION}

\subsection{Design of the experimental setup}

The experimental setup shown in Fig. 1 entails a $1.9 \mathrm{~m}$ tall steel structure, which is seismically isolated using four friction pendulum bearings. The seismically isolated structure is excited by an ensemble of earthquake ground motion excitations using the $2 \mathrm{~m} \times 1 \mathrm{~m}$ unidirectional shaking table of the ETH Laboratory.

The steel structure was designed with a fixed-base vibration period $T_{n}=0.5 \mathrm{~s}$, similar to the one of a 2-4 story building. The structure comprises a steel frame with a lumped mass $m_{s}=250 \mathrm{~kg}$ rigidly fixed on top. The frame consists of two hollow rectangular columns connected at regular intervals by seven horizontal struts. A mechanical clevis connection consisting of two hinge elements and a couple of replaceable steel coupons was designed to enable a 
parametric investigation of the inelastic response of the structure for varying strength values. The two steel coupons shown in Fig. 2 (Nominal size: M16, Body Diameter $D=16 \mathrm{~mm}$, Thread pitch $=1.5 \mathrm{~mm}$ ) with nominal strength $f_{y}=275 \mathrm{MPa}$ are inserted between this steel plate and another bottom steel plate, thus restraining the hinge rotation through their axial deformation. The steel coupons are designed to yield before the other components of the structure, thus concentrating the inelastic behavior of the structure in a plastic hinge. Two different diameters, $D_{\text {red }}=4 \mathrm{~mm}$ and $D_{\text {red }}=5 \mathrm{~mm}$, were used for the reduced section of the M16 steel coupons (Fig. 2).

The seismic isolation system comprises four friction pendulum bearings (Fig. 3) manufactured by the company Mageba SA (Fig. 1). The radius of curvature of each bearing was $1.5 \mathrm{~m}$, leading to a fundamental natural period of the isolated structure $T_{b}=2 \pi \sqrt{\frac{R}{g}}=2.46 \mathrm{~s} \approx 5 T_{n}$, while the bearing displacement capacity was $0.15 \mathrm{~m}$. The coefficient of friction of the sliding bearings for a vertical stress $\sigma_{v}=0.88 \mathrm{MPa}$ was $\mu_{f}=0.0405$. A $30 \mathrm{~cm}$ thick steel base plate with mass $m_{b}=665 \mathrm{~kg}$ and dimensions of $2.1 \mathrm{~m} \times 1.35 \mathrm{~m}$ is fixed on top of the isolators to enable the horizontal diaphragm function of the seismic isolation system.
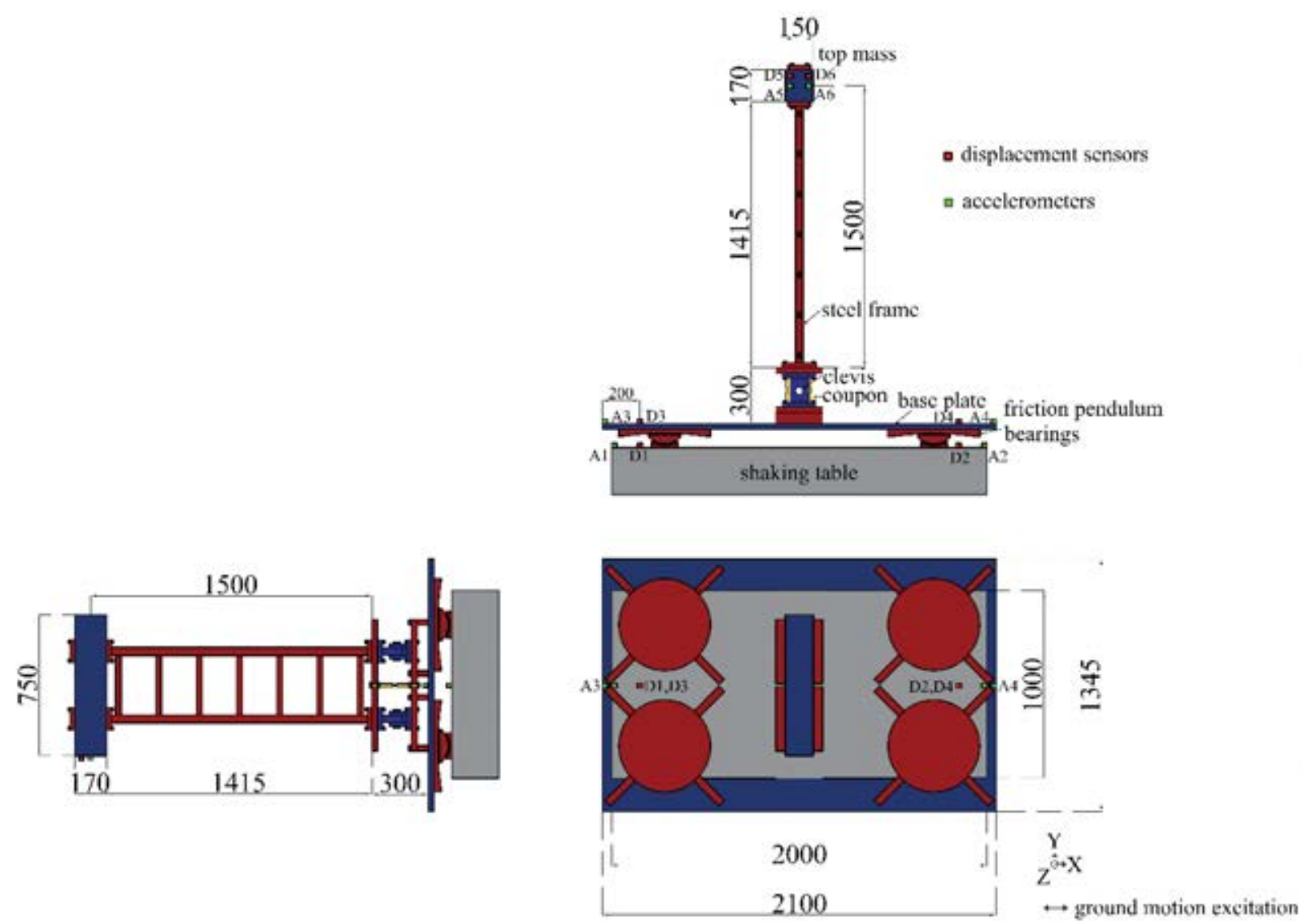

Fig. 1. Top and side views of the designed seismically isolated structure (Dimensions in $\mathrm{mm}$ ). 


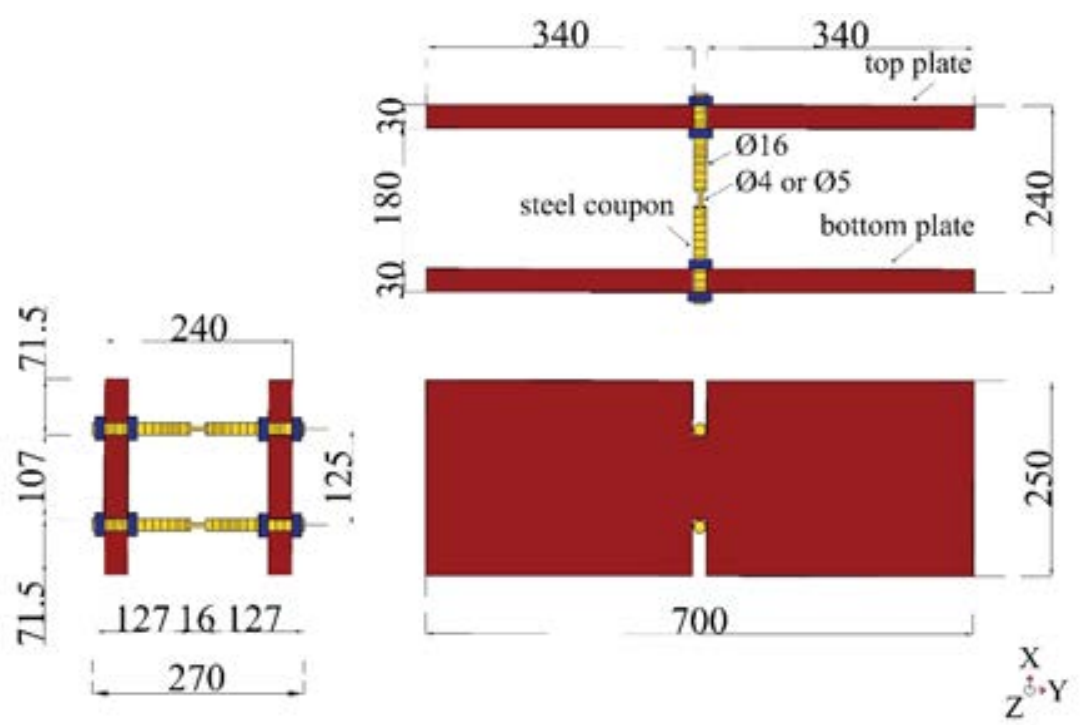

Fig. 2. Top view and cross sections of the mechanical configuration comprising two replaceable steel coupons (Dimensions in $\mathrm{mm}$ ).

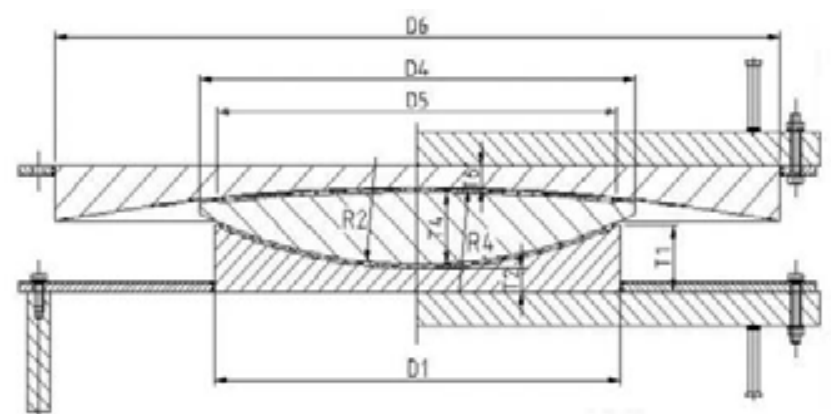

$\begin{array}{ll}\mathrm{D}_{1}=77 \mathrm{~mm} & \mathrm{~T}_{1}=26 \mathrm{~mm} \\ \mathrm{D}_{4}=96 \mathrm{~mm} & \mathrm{~T}_{2}=13.7 \mathrm{~mm} \\ \mathrm{D}_{5}=60 \mathrm{~mm} & \mathrm{~T}_{4}=35.5 \mathrm{~mm} \\ \mathrm{D}_{6}=320 \mathrm{~mm} & \mathrm{~T}_{6}=23 \mathrm{~mm} \\ \mathrm{R}_{2}=60 \mathrm{~mm} & \mathrm{R}_{4}=1500 \mathrm{~mm}\end{array}$

Fig. 3. Drawing of the friction pendulum bearings used in the experimental setup, as designed by the company Mageba SA.

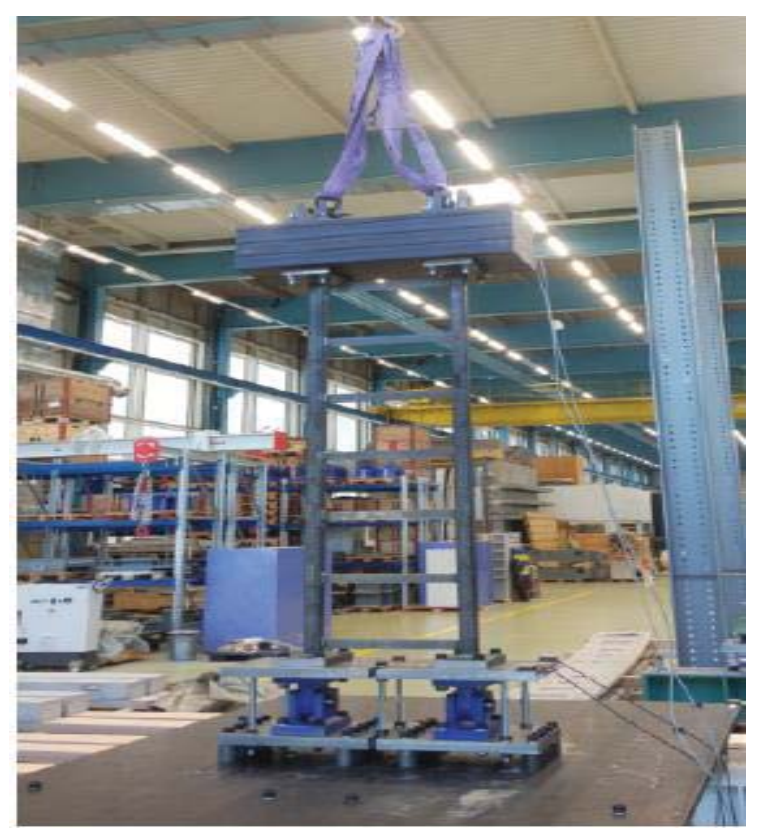

Fig. 4. Constructed experimental setup at the ETH Structures Laboratory. 


\subsection{Ground motion ensemble}

The seismically isolated structure shown in Fig. 1 was excited by 8 different ground motion records obtained from the PEER Strong Ground Motion Database. The characteristics of the applied records are shown in Table 1. The recorded motions, scaled to different Peak Ground Acceleration (PGA) levels, are applied in the X-direction of the experimental setup shown in Fig. 1, using the unidirectional shaking table of the ETH Structures Laboratory with a stroke $d_{\max }=240 \mathrm{~mm}$. Each ground motion record was applied twice to the seismically isolated structure, characterized by two different strength values: First, a seismically isolated structure with strength reduction factor $R_{y}=1.5$, engineered through the use of steel coupons with reduced section (Fig. 2) of diameter $D_{\text {red }}=5 \mathrm{~mm}$, was subjected to the ground motion record. Second, a seismically isolated structure with strength reduction factor $R_{y}=2$, engineered through the use of steel coupons with reduced section (Fig. 2) of diameter $D_{\text {red }}=4 \mathrm{~mm}$, was subjected to the same ground motion record.

\subsection{Instrumentation}

The attachment of 6 uniaxial accelerometers and 6 displacement markers to the experimentally investigated structure shown in Fig. 1 enables the continuous monitoring of the acceleration and the displacement time history response of the structure during the shaking table motion.

Table 1. List of recorded earthquake ground motions used for the excitation of the steel structure (PEER NGA Database, 2019 [18]).

\begin{tabular}{|c|c|c|c|c|c|}
\hline No. & Date & Earthquake and Station & $\begin{array}{c}\text { PGA of the } \\
\text { original } \\
\text { motion }(\mathrm{g})\end{array}$ & $\begin{array}{c}\text { Amplitude } \\
\text { scaling of } \\
\text { the original } \\
\text { motion }\end{array}$ & $\begin{array}{c}\text { PGA of } \\
\text { the scaled } \\
\text { motion (g) }\end{array}$ \\
\hline 1 & $9 / 2 / 1971$ & $\begin{array}{c}\text { San Fernando, 279 Pacoima } \\
\text { Dam }\end{array}$ & 1.23 & $35 \%$ & 0.43 \\
\hline 2 & $17 / 1 / 1994$ & $\begin{array}{c}\text { Northridge, USGS/VA 637 } \\
\text { LA-Sepulveda VA Hospital }\end{array}$ & 0.75 & $75 \%$ & 0.56 \\
\hline 3 & $02 / 5 / 1982$ & $\begin{array}{c}\text { Coalinga, 1651 Transmitter } \\
\text { Hill station }\end{array}$ & 0.84 & $100 \%$ & 0.84 \\
\hline 4 & $16 / 9 / 1978$ & Tabas, 9101 & 0.84 & $32.5 \%$ & 0.27 \\
\hline 5 & $20 / 9 / 1999$ & Chi-Chi, CHY 080 & 0.97 & $40 \%$ & 0.39 \\
\hline 6 & $16 / 01 / 1995$ & Kobe, KJMA & 0.82 & $65 \%$ & 0.53 \\
\hline 7 & $18 / 10 / 1989$ & $\begin{array}{c}\text { Loma Prieta, } \\
\text { UCSC 16 LGPC }\end{array}$ & 0.97 & $17.5 \%$ & 0.17 \\
\hline 8 & $24 / 04 / 1984$ & $\begin{array}{c}\text { Morgan Hill, } \\
57217 \text { Coyote Lake Dam }\end{array}$ & 0.71 & $100 \%$ & 0.71 \\
\hline
\end{tabular}




\section{SHAKING TABLE INVESTIGATION}

\subsection{Response dominated by inelastic behaviour of the seismically isolated structure}

The presented structure (Fig. 1) was first excited by the 17.5\% scaled-down 1989 Loma Prieta ground motion acceleration record (No. 7 in Table 1), shown in Fig. 5. The experimentally derived displacement time history response of the isolated structure designed with a strength reduction factor $R_{y}=1.5$ relative to the isolators is shown in Fig. 6. The experimentally observed displacement time history response of the seismic isolation system relative to the shaking table motion is shown in the same Figure.

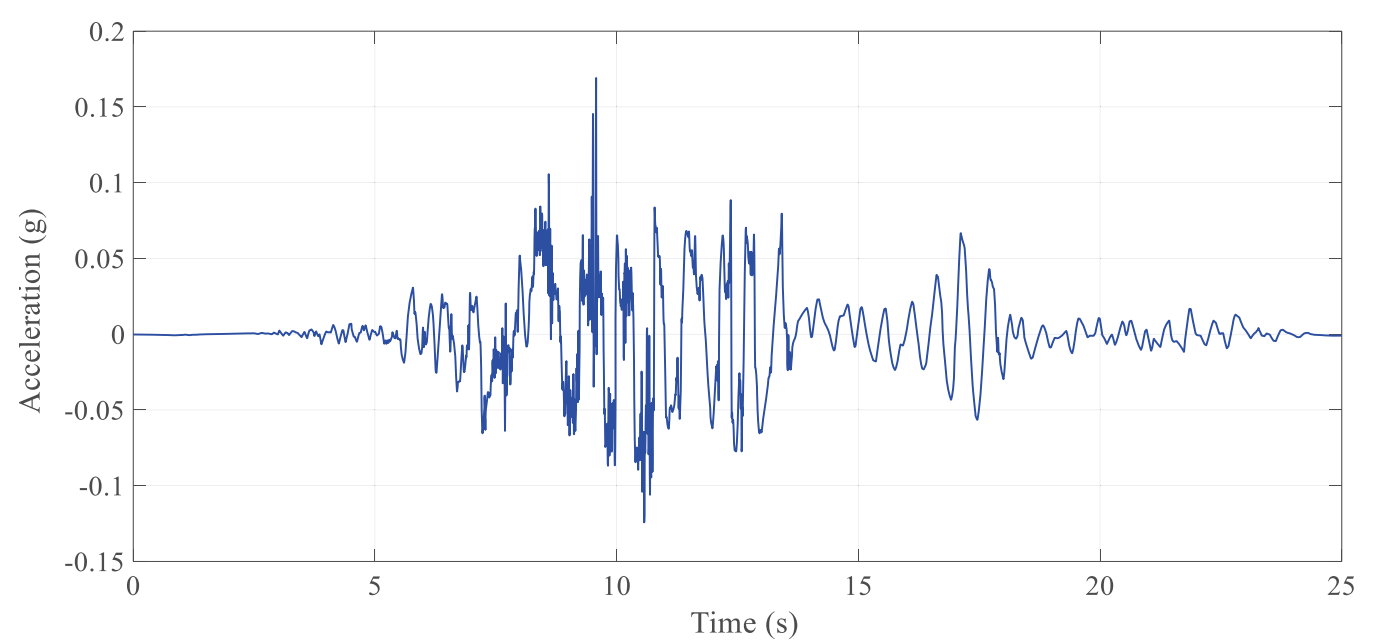

Fig. 5. 17.5\%-scaled Loma Prieta ground motion acceleration record.

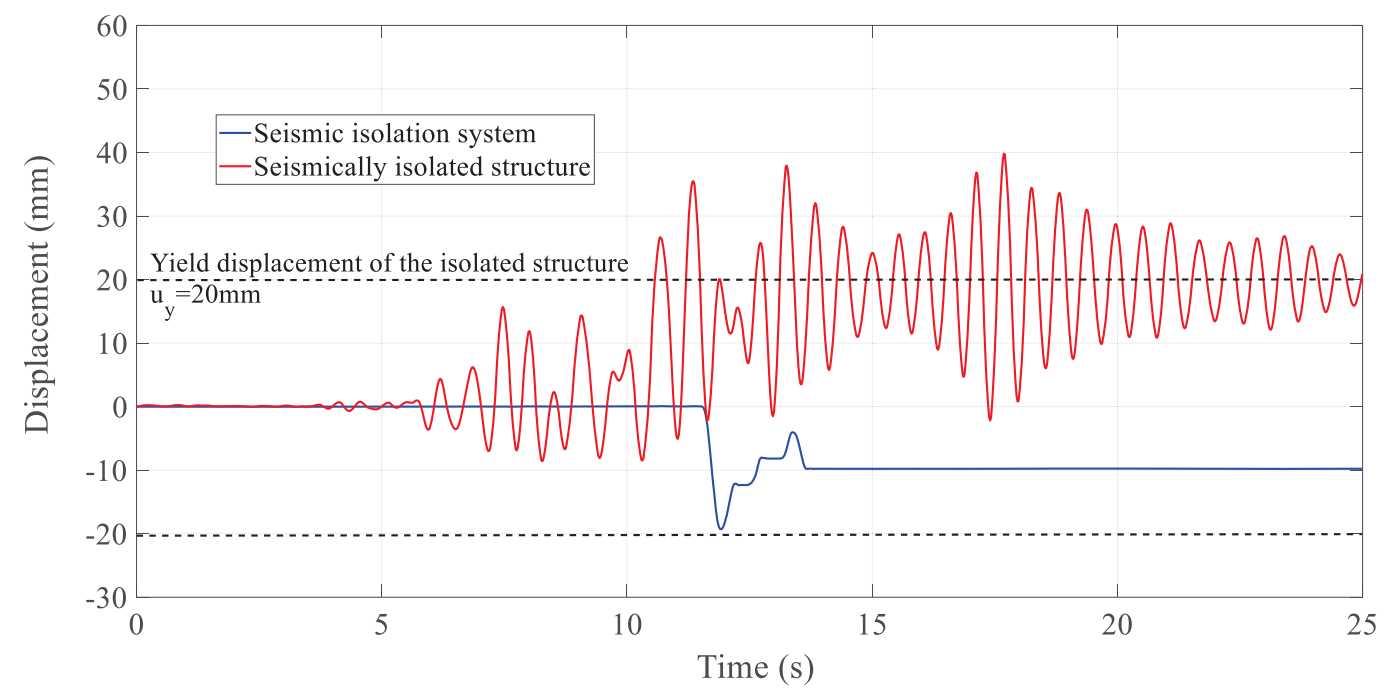

Fig. 6. Displacement time history response of the seismically isolated structure with a strength reduction factor $R_{y}=1.5$ and the seismic isolation system subjected to the $17.5 \%$-scaled Loma Prieta ground motion.

After the initiation of yielding, the isolated structure manifested significant inelastic behavior, leading to a maximum inelastic displacement $u_{\max }=40.2 \mathrm{~mm}$ and a ductility demand $\mu=u_{\max } / u_{y}=40.2 \mathrm{~mm} / 20 \mathrm{~mm}=2.01$. The maximum sliding displacement of the seismic isolation 
system was not significant for this ground motion excitation, reaching a maximum value of $19.8 \mathrm{~mm}$ for a dimensionless friction ratio $\Pi_{2}=\mu_{f} \mathrm{~g} / \mathrm{PGA}=0.62$, as defined by Tsiavos et al. [15].

\subsection{Response dominated by the sliding displacement of the seismic isolation system}

The experimentally derived response of the seismic isolation system was substantially different when the seismically isolated structure (Fig. 1) was subjected to the $35 \%$ scaled-down San Fernando ground motion acceleration record (No. 1 in Table 2), shown in Fig. 7.

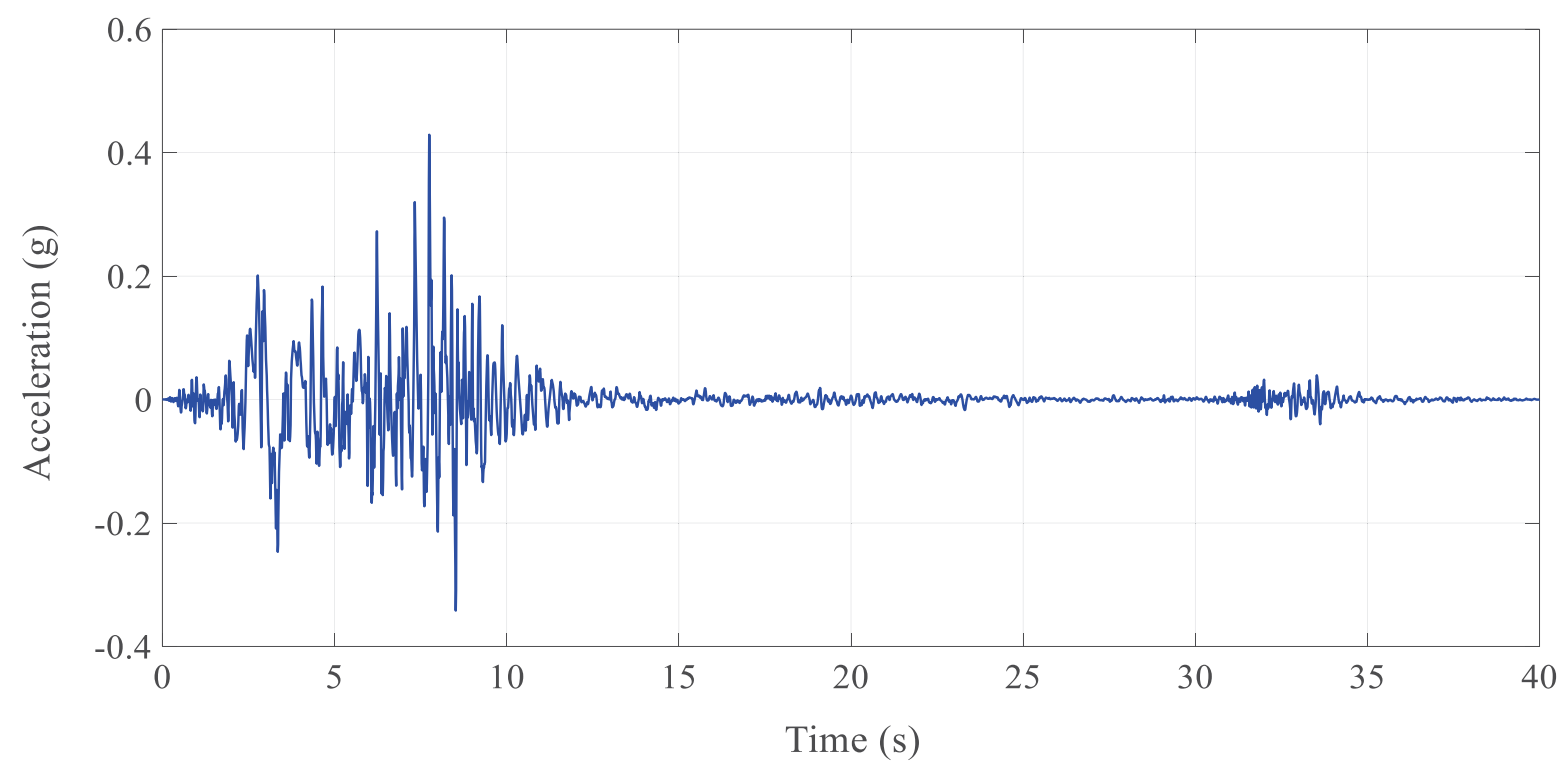

Fig. 7. 35\%-scaled San Fernando ground motion acceleration record.

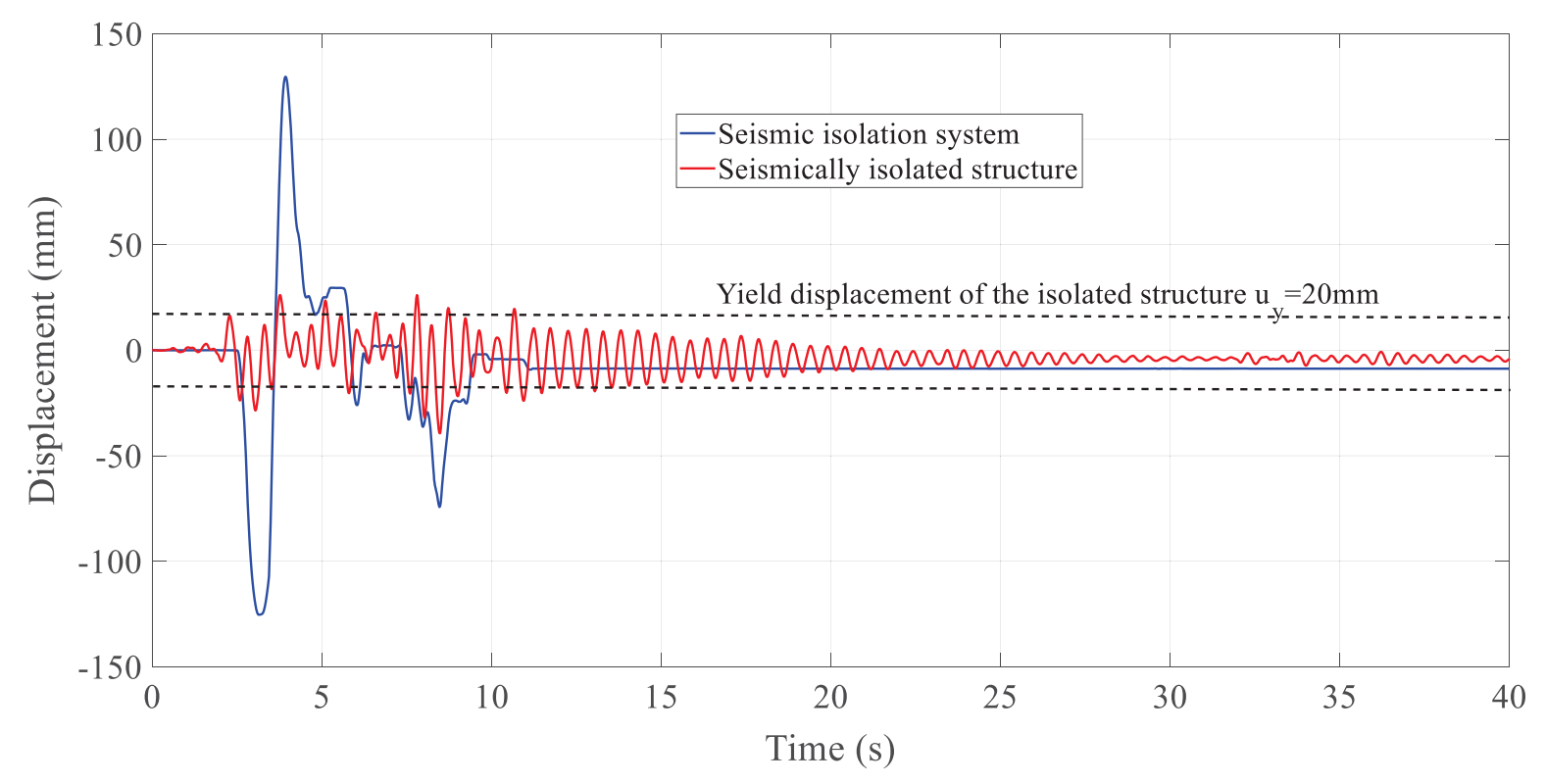

Fig. 8. Displacement time history response of the seismically isolated structure with a strength reduction factor $R_{y}=1.5$ and the seismic isolation system subjected to the 35\%-scaled San Fernando ground motion. 
As shown in the displacement time history response of Fig. 8, the isolated structure manifested significant inelastic behavior in this case as well, despite the earlier and more pronounced activation of the seismic isolation system. The emerging ductility demand in this case (for the same strength reduction factor $R_{y}=1.5$ ) in the isolated structure was $\mu=u_{\max } / u_{y}=37.4 \mathrm{~mm} / 20 \mathrm{~mm}=1.87$. Furthermore, the maximum sliding displacement of the seismic isolation system relative to the shaking table was in this case $125 \mathrm{~mm}$, much higher than the corresponding sliding displacement of $19.8 \mathrm{~mm}$ observed for the Loma Prieta ground motion. This large sliding displacements usually manifest themselves during excitations of the seismically isolated structure by long-period ground motion records, as observed by Tsiavos et al. [19, 20], Banovic et al. [21], De Domenico et al. [22] and Gandelli et al. [23].

\subsection{Damage Type}

Two different limit states have been identified in this study to quantify the potential occurrence of damage in a seismically isolated structures: The exceedance of a predetermined ductility demand level in the seismically isolated structure indicating damage in the structure; and the exceedance of a predefined isolator displacement, which is related to a potential damage in the isolators.

The exceedance of the ductility demand level $\mu=2$ was chosen to quantify the manifestation of severe damage in the isolated structure. As the current code provisions for seismically isolated structures prescribe the elastic design of these structures, the detailing of these structures is usually not sufficient to facilitate high ductility capacity in the isolated structure.

The exceedance of an isolator displacement corresponding to $90 \%$ of the isolator displacement capacity $\mathrm{d}=150 \mathrm{~mm}$ was chosen to quantify the occurrence of damage in the seismic isolation system. Furinghetti et al. [5] have experimentally evaluated and determined the extrastroke displacement capacity of curved surface slider devices, which is limited by the maximum contact pressure that can be tolerated by the installed sliding material. This extra-stroke displacement capacity was not considered in this study, but it can be further investigated by future studies on the same topic.

As shown in Tables 2 and 3, the value of the dimensionless friction ratio $\Pi_{2}=\mu \mathrm{g} / \mathrm{PGA}$, as defined by [15], indicated the predominant response and damage mode of the system for the case of a strength reduction factor of the isolated structure $R_{y}=1.5$ : Values of $\Pi_{2}$ smaller than $20 \%$ were correlated with high sliding displacement and potential damage in the seismic isolation system. Nevertheless, values of $\Pi_{2}$ greater than $30 \%$ led to high ductility demand and damage concentrated in the seismically isolated structure. This variability in the response modes of the system for $R_{y}=1.5$ indicates that the response is also influenced by the frequency content of the ground motion characteristics.

However, the design of a weaker isolated structure with $R_{y}=2$ led to high ductility demand and concentration of damage in the seismically isolated structure for all the ground motion records used in this study. The sliding displacement of the seismic isolation system was substantially lower in this case, indicating that the response mode of the isolated structure subjected to extreme earthquake events is significantly influenced by the strength of the isolated structure: The reduction of the strength of the isolated structure leads to higher amount of damage in the isolated structure, which is not influenced by the ground motion characteristics. 
Table 2. Experimentally and analytically derived response for $R_{y}=1.5$.

\begin{tabular}{|c|c|c|c|c|c|}
\hline No. & $\begin{array}{c}\text { Strength } \\
\text { reduction } \\
\text { factor } \\
R_{y}\end{array}$ & $\begin{array}{c}\text { Experimentally } \\
\text { observed } \\
\text { ductility demand } \\
\mu\end{array}$ & $\begin{array}{c}\text { Dimensionless } \\
\text { friction ratio } \\
\Pi_{2}(\%)\end{array}$ & $\begin{array}{c}\text { Experimentally } \\
\text { observed } \\
\text { maximum sliding } \\
\text { displacement of the } \\
\text { seismic isolation } \\
\text { system (mm) }\end{array}$ & Damage type \\
\hline 1 & 1.5 & 1.87 & 24 & 125 & - \\
\hline 2 & 1.5 & 1.96 & 19 & 148.3 & $\begin{array}{c}\text { Seismic isolation } \\
\text { system }\end{array}$ \\
\hline 3 & 1.5 & 1.78 & 13 & 147.4 & $\begin{array}{c}\text { Seismic isolation } \\
\text { system }\end{array}$ \\
\hline 4 & 1.5 & 2.03 & 39 & 56.9 & Isolated structure \\
\hline 5 & 1.5 & 2.23 & 30 & 77.6 & Isolated structure \\
\hline 6 & 1.5 & 1.81 & 20 & 150 & $\begin{array}{c}\text { Seismic isolation } \\
\text { system }\end{array}$ \\
\hline 7 & 1.5 & 2.01 & 62 & 19.8 & Isolated structure \\
\hline 8 & 1.5 & 1.82 & 15 & 143 & $\begin{array}{c}\text { Seismic isolation } \\
\text { system }\end{array}$ \\
\hline
\end{tabular}

Table 3. Experimentally and analytically derived response for $R_{y}=2$.

\begin{tabular}{|c|c|c|c|c|c|}
\hline No. & $\begin{array}{c}\text { Strength } \\
\text { reduction } \\
\text { factor } \\
R_{y}\end{array}$ & $\begin{array}{c}\text { Experimentally } \\
\text { observed } \\
\text { ductility } \\
\text { demand } \mu\end{array}$ & $\begin{array}{c}\text { Dimensionless } \\
\text { friction ratio } \\
\Pi_{2}(\%)\end{array}$ & $\begin{array}{c}\text { Experimentally } \\
\text { observed } \\
\text { maximum sliding } \\
\text { displacement of the } \\
\text { seismic isolation } \\
\text { system (mm) }\end{array}$ & Damage type \\
\hline 1 & 2.0 & 2.92 & 24 & 117.3 & Isolated structure \\
\hline 2 & 2.0 & 2.81 & 19 & 135.8 & Isolated structure \\
\hline 3 & 2.0 & 2.77 & 13 & 139.2 & Isolated structure \\
\hline 4 & 2.0 & 3.08 & 39 & 55.1 & Isolated structure \\
\hline 5 & 2.0 & 3.17 & 30 & 72.4 & Isolated structure \\
\hline 6 & 2.0 & 2.45 & 20 & 131.2 & Isolated structure \\
\hline 7 & 2.0 & 3.38 & 62 & 16.7 & Isolated structure \\
\hline 8 & 2.0 & 2.76 & 15 & 129.5 & Isolated structure \\
\hline
\end{tabular}

\section{CONCLUSIONS}

This study shows experimentally the effect of the design parameters of the seismic isolation system and the seismically isolated structure on the response modes of seismically isolated structures subjected to extreme earthquake events. This effect is demonstrated through a shaking table investigation of the response of a seismically isolated steel structure, subjected to a strong earthquake ground motion excitation ensemble. The tested steel structure was seismically isolated with four friction pendulum bearings. The steel structure was equipped with a mechanical clevis connection comprising two hinges and a pair of replaceable steel coupons. The coupons are designed to yield before the other components of the structure and can be replaced after every shaking table test, thus allowing the experimental seismic fragility analysis of structures. 
The shaking table investigation demonstrated the two different fundamental response modes of seismically isolated structures, subjected to above-design earthquake ground motion excitation: A mode characterized by excessive damage of the seismically isolated structure but limited damage in the isolators and a mode dominated by excessive isolator displacement and less damage in the isolated structure.

The two different seismic damage modes of a seismically isolated structure emerging from these two response modes were quantified based on two selected limit states. For the case of a seismically isolated structure designed with a strength reduction factor $R_{y}=1.5$, both damage modes were observed. These modes were strongly correlated with the value of the dimensionless friction ratio $\Pi_{2}$ : Values of $\Pi_{2}$ smaller than $20 \%$ were correlated with damage in the seismic isolation system, while values of $\Pi_{2}$ bigger than $30 \%$ led to damage concentrated in the seismically isolated structure. However, the weaker seismically isolated structure designed with $R_{y}=2$ manifested only damage in the isolated structure and lower sliding displacement of the isolation system, when subjected to the same ground motion excitation ensemble.

\section{REFERENCES}

[1] S. Kitayama, M.C. Constantinou, Implications of strong earthquake ground motion duration on the response and testing of seismic isolation systems. Earthquake Engineering and Structural Dynamics, 50 (2), 290-308, 2021.

[2] S. Kitayama, M.C. Constantinou, Effect of superstructure modeling assumptions on the seismic performance of seismically isolated buildings. Earthquake Engineering and Structural Dynamics, 2021, DOI: https://doi.org/10.1002/eqe.3427

[3] K. Gkatzogias, A. Kappos, Direct estimation of seismic response in reduced degree of freedom isolation and energy dissipation systems. Earthquake Engineering and Structural Dynamics, 48 (10), 1112-1133, 2019, DOI: https://doi.org/10.1002/eqe.3169

[4] M. Furinghetti, I. Lanese, A. Pavese, Experimental assessment of the seismic response of a base-isolated building through a hybrid simulation. Recent Advances and Applications of Seismic Isolation, Frontiers in Built Environment, 6 (33), 2021, DOI: https://doi.org/10.3389/fbuil.2020.00033.

[5] M. Furinghetti, T. Yang, P.M. Calvi, A. Pavese, Experimental evaluation of extra-stroke displacement capacity for curved surface slider devices. Soil Dynamics and Earthquake Engineering, 2021, DOI: https://doi.org/10.1016/j.soildyn.2021.106752.

[6] M. Furinghetti, A. Pavese. Definition of a Simplified Design Procedure of Seismic Isolation Systems for Bridges, Structural Engineering International, 2020, DOI: 10.1080/10168664.2020.1775535.

[7] A. Tsiavos, B. Stojadinovic, A probabilistic approach towards and evaluation of existing code provisions for seismically isolated structures, European Congress on Computational Methods in Applied Sciences and Engineering (ECCOMAS), Crete Island, Greece, 5-10 June 2016.

[8] P. Castaldo, B. Palazzo, P. Della Vecchia, Seismic reliability of base-isolated structures with friction pendulum bearings. Engineering Structures, 95, 80-93, 2015.

[9] P. Castaldo, M. Ripani, R.L. Priore, Influence of soil conditions on the optimal sliding friction coefficient for isolated bridges. Soil Dynamics and Earthquake Engineering, 111, 131-148. 2018. 
[10]H.H. Tsang, Seismic isolation by rubber-soil mixtures for developing countries. Earthquake Engineering and Structural Dynamics, 37, 283-303, 2008.

[11] Y.B. Peng, Y.Y. Ma, T.C. Huang, D. De Domenico, Reliability-based design optimization of adaptive sliding base isolation system for improving seismic performance of structures. Reliability Engineering and System Safety, 205, 107167, 2021.

[12] M. Kikuchi, C.J. Black, I.D. Aiken, On the response of yielding seismically isolated structures. Earthquake Engineering and Structural Dynamics, 37, 659-679, 2008.

[13] D. Cardone , A. Flora, G. Gesualdi, Inelastic response of RC frame buildings with seismic isolation. Earthquake Engineering and Structural Dynamics, 42, 871-889, 2013. doi: $10.1002 /$ eqe. 2250

[14] L. Ragni, D. Cardone, N. Conte, A. Dall'Asta, A. Di Cesare, A. Flora, G. Leccese, F. Micozzi, C. Ponzo, Modelling and Seismic Response Analysis of Italian Code Conforming Base-Isolated Buildings. Journal of Earthquake Engineering, 22 (2), 198-230, 2018, DOI: 10.1080/13632469.2018.1527263.

[15] A. Tsiavos, K.R. Mackie, M.F. Vassiliou, B. Stojadinovic, Dynamics of inelastic baseisolated structures subjected to recorded ground motions. Bulletin of Earthquake Engineering, 15(4), 1807-1830, 2017.

[16] A. Tsiavos, D. Schlatter, T. Markic, B. Stojadinovic, Experimental and analytical investigation of the inelastic behavior of structures isolated using friction pendulum bearings. Procedia engineering, 199, 465-70, 2017.

[17] A. Tsiavos, D. Schlatter, T. Markic, B. Stojadinovic, Shaking table investigation of inelastic deformation demand for a structure isolated using friction-pendulum sliding bearings. Structures, 31, 1041-1052, 2021. DOI: https://doi.org/10.1016/j.istruc.2021.02.040

[18] PEER NGA Strong Motion Database (2018) Pacific Earthquake Engineering Research Center, University of California, Berkeley, available at. https://ngawest2.berkeley.edu/.

[19] A. Tsiavos, A. Sextos, A. Stavridis, M. Dietz, L. Dihoru, N. Alexander. Large-scale experimental investigation of a low-cost PVC 'sand-wich' (PVC-s) seismic isolation for developing countries. Earthquake Spectra, 36(4), 1886-911, 2020.

[20] A. Tsiavos, P. Haladij, A. Sextos, N. Alexander, Analytical investigation of the effect of a deformable sliding layer on the dynamic response of seismically isolated structures Structures, 27, 2426-2436, 2020.

[21] I. Banovic, J. Radnić, N. Grgić. Foundation size effect on the efficiency of seismic base isolation using a layer of stone pebbles. Earthquakes and Structures, 19 (2), 2020.

[22] D. De Domenico, E. Gandelli, V. Quaglini, Adaptive isolation system combining low friction sliding pendulum bearings and SMA-based gap dampers. Engineering Structures, 212, 2020.

[23] E. Gandelli, D. De Domenico, P. Dubini, M. Besio, E. Bruschi, V. Quaglini. Influence of the breakaway friction on the seismic response of buildings isolated with curved surface sliders:parametric study and design recommendations. Structures, 27,788-81, 2020. 